\title{
The Effects of Lower Extremitiy Muscle Strengthening Exercise and Treadmill Walking Exercise on the Gait and Balance of Stroke Patients
}

\author{
Chang Sook Kim, PT, MS ${ }^{1)}$, Wontae Gong, PhD, PT ${ }^{2)}$, Shin Gyun KIM, $\mathrm{PT}^{3)}$ \\ 1) Physical Therapy, Department of Rehabilitation Science, Graduate School of Daegu Univestiy: 14 \\ Jillyang, Gyeongsan-si, Gyeongbuk, 712-714 Republic of Korea. TEL: +82 53-850-5032, \\ FAX:+82 53-850-5039,E-mail:canpt@naver.com \\ 2) Department of Physical Therapy, Gumi College \\ ${ }^{3)}$ Seodaegu Jin Hospital
}

\begin{abstract}
Purpose] We investigated the effect of lower extremity muscle strengthening exercise and treadmill walking exercise on the gait and balance of stroke patients. [Subjects] The subjects were 44 stroke patients and they were randomly assigned to the lower extremity muscle strengthening group (MSG, $\mathrm{n}=24$ ) and the treadmill walking group $(\mathrm{TWG}, \mathrm{n}=20)$. [Methods] Both groups performed the exercises 3 times a week for 6 weeks in addition to general physical therapy. Walking ability was evaluated using the $10 \mathrm{~m}$ walking test and the timed up-and-go test (TUG), and balance ability was evaluated using the Berg Balance Scale (BBS) and a balance performance monitor (BPM). [Results] There was no difference between the groups in the $10 \mathrm{~m}$ walking test and TUG with respect to walking ability, but walking ability was significantly improved after the exercise in each group when compared to before the exercise. [Conclusion] It was found that both the lower extremity muscle strengthening exercise and the treadmill walking exercise helped the stroke patients to improve their walking ability, but it is hard to decide which exercise is more effective.

Key words: Stroke, Balance, Walking
\end{abstract}

(This article was submitted Nov. 1, 2010, and was accepted Nov. 30, 2010)

\section{INTRODUCTION}

Stroke causes long-term impairment and it reduces mobility. A lack of motor ability in the lower extremity affects walking ability and balance and increases the risk of a fall ${ }^{1)}$. The reduced walking ability of hemiplegic patients is caused by flaccidity, spasticity, and dysfunction of the lower extremity of the affected side and is a key factor in preventing patients from achieving full independence ${ }^{2)}$. A treadmill is widely used as a treatment method for improving the walking ability of stroke patients. A treadmill provides repeated and rhythmic walking motions in an upright position with the body weight supported by the lower extremities ${ }^{3)}$. Treadmill exercise is therapeutically used as a walking exercise with the body weight supported and with the body weight unsupported. It was reported that treadmill walking provides not only a treatment for standing, but also for the muscle-strengthening, balance and motor control required for walking ${ }^{4}$. Body weight supported treadmill walking was reported to be effective for improving the gait of the subjects who were able to walk independently during the treatment ${ }^{5}$. Additionally, it was also reported that walking exercise without any body weight support improved the symmetry of the stride length in chronic hemiplegic patients ${ }^{6}$.

Weakened muscle strength, one of the chronic symptoms of stroke patients, is a factor that limits functional rehabilitation. Sharp stated that muscle-strengthening exercise is important because the extensibility of the knee joint is increased through lower extremity muscle strength training and increased lower extremity muscle strength is closely associated with an increase in walking speed ${ }^{7}$. It was also reported that a lower extremity muscle strengthening program increased the strength of the extensors and flexors of the hip joint, the extensors and flexors of the knee joint, and the sole flexors and dorsum flexors of the ankle joint, as well as subjects' performance in static and dynamic balance tests ${ }^{8}$.

However, previous studies on the improvement of gait and balance of stroke patients have focused on the effect on walking ability. Studies of walking and balance ability have performed muscle strengthening exercises using expensive constant speed muscle strengthening equipment that are hardly ever used by stroke patients. Therefore, in this study, we investigated the effects of lower extremity muscle strengthening exercise on the gait and balance of stroke 
patients using lower extremity muscle strengthening equipment that is widely available in clinical treatment situations, and compared the results with those of treadmill walking exercise.

\section{SUBJECTS AND METHODS}

In this study, the subjects were patients of W hospital located in Daegu, Korea, and they performed walking exercise or lower extremity muscle strengthening exercise for $30 \mathrm{~min}, 3$ times a week, for 6 weeks. In addition, both groups received neurodevelopmental treatment for $30 \mathrm{~min}$ once a day, five times a week and FES (functional electrical stimulation) treatment for 20 min once a day, five times a week. The subjects were individuals who had hemiplegic resulting from stroke for more than 3 months. They were able to maintain a standing position independently for more than 30 seconds and could walk indoors continuously for more than $30 \mathrm{~m}$ independently. Also, they had no problems with walking due to orthopedic surgery or impairment, a Modified Ashworth Scale stiffness 2 or less and a lower extremity muscle strength measured as $\mathrm{F}$ or higher in the Manual Muscle Test. All subjects were able to understand and follow the instructions of the researchers and voluntarily participated in the study. They were given sufficient explanation about the intention and procedure of the overall experiment and they provided their informed consent.

The Chi-square test was used to analyze the gender of all the participants in the study and the independent t-test was used to examine subjects' age, height, body weight, type of paralysis, type of stroke, and the duration of disorder. The two groups were statistically homogeneous, since no significant difference was found in the analyses $(\mathrm{p}>0.05)$ (Table 1). The characteristics of the participants were verified through the medical records of the hospital and 20 of subjects were allocated to the treadmill walking group

Table 1. General characteristics of the subjects (mean $\pm \mathrm{SD})$

\begin{tabular}{|c|c|c|}
\hline & $\operatorname{MSG}(n=24)$ & TWG $(n=20)$ \\
\hline \multirow{2}{*}{ Gender } & Male: 14 & Male: 11 \\
\hline & Female: 10 & Female: 9 \\
\hline Age (year) & $50.10 \pm 7.8$ & $51.37 \pm 4.1$ \\
\hline Height (cm) & $169.20 \pm 9.2$ & $167.00 \pm 9.5$ \\
\hline Weight (kg) & $65.20 \pm 11.3$ & $68.25 \pm 8.1$ \\
\hline \multirow{2}{*}{ Paretic side } & Right: 16 & Right: 12 \\
\hline & Left: 8 & Left: 8 \\
\hline \multirow{2}{*}{ Type of stroke } & Infarction: 14 & Infarction: 9 \\
\hline & ICH: 10 & ICH: 11 \\
\hline $\begin{array}{c}\text { Time since } \\
\text { Stroke (mon.) }\end{array}$ & $14.30 \pm 3.4$ & $14.75 \pm 6.1$ \\
\hline
\end{tabular}

(TWG) and 24 to the muscle strengthening group (MSG). For TWG, the exercise was performed in 30 minute sessions using EN-MILL (ENRAF NONIUS Company, Netherlands) in the speed range in which the independency or stability of walking did not decline, gradually increasing the walking speed from $1.0 \mathrm{~km} / \mathrm{h}$ up to $2.5 \mathrm{~km} / \mathrm{h}$ depending on the conditon of the individual patients. For MSG, the exercise was performed using lower extremity muscle strengthening equipment (Model EN-Dynamic Seated Leg press, Model EN-Dynamic knee extension, Model ENDynamic Leg Abductor, ENRAF NONIUS company, Netherlands). The load was $40 \%$ of 1 repetition maximum (RM), which is the intensity used for the elderly in muscle strengthening, 30 times in each of 2 sets at one equipment station, with 5 minutes of rest between the sets. From the fourth week of the experiment, the subjects did 3 sets at each equipment station, and the intensity was increased up $60 \%$ of 1 RM.

The evaluations of walking and balance ability were carried out before the start of the exercise program and 6 weeks after the start of the program. To measure walking ability, we used the $10 \mathrm{~m}$ walking test and the timed upand- go (TUG) test. For the measurement of balance ability, a balance performance monitor (BPM) that was made by SMS Healthcare, UK, and for which the validity has been was verified through a single-case experimental design, and a Berg Balance Scale (BBS) were used.

The experimental results were statistically analyzed using SPSS 12.0 KO (SPSS, Chicago, IL, USA). After the general characteristics of the subjects were determined, paired t-tests were used to compare the changes in gait and balance between pre and post-interventiont in each group. The differences between the 2 groups were tested using the independent t-tests. The level of statistical significance $\alpha$, chosen at 0.05 .

\section{RESULTS}

The paired samples t-test was performed to compare the results of the $10 \mathrm{~m}$ walking test, TUG, BBS, and dynamic average balance of TWG and MSG before and after the

Table 2. A comparison of walking and balance ability within the groups $($ mean $\pm \mathrm{SD})$

\begin{tabular}{|c|c|c|c|}
\hline & Category & Pre-test & Post-test \\
\hline \multirow{4}{*}{$\begin{array}{l}\text { MSG } \\
(\mathrm{n}=24)\end{array}$} & $10 \mathrm{~m}$ walk test (sec)* & $22.3 \pm 15.5$ & $16.9 \pm 13.4$ \\
\hline & TUG (sec)* & $26.0 \pm 18.2$ & $19.3 \pm 13.6$ \\
\hline & BBS $($ score)** & $37.6 \pm 6.4$ & $49.6 \pm 2.6$ \\
\hline & Dynamic mean balance (\%)* & $61.8 \pm 8.8$ & $53.1 \pm 2.0$ \\
\hline \multirow{4}{*}{$\begin{array}{l}\text { TWG } \\
(n=20)\end{array}$} & $10 \mathrm{~m}$ walk test (sec)* & $24.4 \pm 12.4$ & $17.2 \pm 7.3$ \\
\hline & TUG (sec)* & $25.9 \pm 10.9$ & $20.1 \pm 9.6$ \\
\hline & BBS (score)* & $37.1 \pm 10.4$ & $46.8 \pm 4.8$ \\
\hline & Dynamic mean balance $(\%)^{*}$ & $68.3 \pm 9.7$ & $57.8 \pm 9.1$ \\
\hline
\end{tabular}

$* \mathrm{p}<0.01, * \mathrm{p}<0.05$ 
Table 3. A comparison of improvements in walking and balance abilities between the two groups $($ mean \pm SD)

\begin{tabular}{ccc}
\hline Category & MSG $(\mathrm{n}=24)$ & TWG $(\mathrm{n}=20)$ \\
\hline 10 m walk test $(\mathrm{sec})$ & $5.5 \pm 3.9$ & $7.2 \pm 6.5$ \\
\hline TUG $(\mathrm{sec})$ & $6.7 \pm 5.8$ & $5.8 \pm 4.9$ \\
\hline BBS $($ score $)$ & $12.0 \pm 4.6$ & $9.6 \pm 6.5$ \\
\hline Dynamic mean balance $(\%)$ & $8.6 \pm 7.9$ & $10.6 \pm 7.4$ \\
\hline
\end{tabular}

experiment. The results show that significant differences were found for all the items in both groups $(\mathrm{p}<0.05)$ (Table 2).

The independent t-test was performed to examine the differences in the $10 \mathrm{~m}$ walking test, TUG, BBS, and dynamic average balance before and after the experiment between TWG and MSG. The results show that there was no significant difference between the two groups in any of the items $(\mathrm{p}<0.05)($ Table 3$)$.

\section{DISCUSSION}

Impaired walking ability after stroke is a great obstacle to the functional independency of patients. Walking exercise using a treadmill provides stroke patients with the advantages of enhancing coordinative exercise of the legs while controlling body weight load during walking and through this an improvement in walking speed is acheived $^{3,9)}$. In addition, a program to increase lower extremity muscle strength and improve balance during walking, walking speed, and walking distance is very effective for stroke patients ${ }^{10)}$. In this study, we investigated the effects of lower extremity muscle strengthening exercise on the gait and balance of stroke patients using a treadmill that is widely applied in clinical treatment and lower extremity muscle strengthening equipment that is readily available.

Decreased lower extremity muscle function of stroke patients greatly affects support, movement, and balance of the body. It impairs not only the ability to use appropriate power, but also inhibits the rapid production of force as it affects the onset, timing, order of use muscle strength, and maintenance and balance of the power ${ }^{11}$. In a previous study examining lower extremity muscle strengthening, 10 weeks of muscle strengthening exercise and aerobic exercise preformed by chronic stroke patients improved their functional performance and quality of life and increased their walking ability ${ }^{12)}$. Additionally, in a study in which chronic stroke patients carried out 10 weeks of muscle strengthening exercises using sandbags and a Theraband in 30 minute sessions 3 times a week, walking speed was improved ${ }^{13)}$. Also, in a study where resistance exercise was carried out at $30-50 \%$ of the maximum muscle strength of the upper and lower extremities for 4 weeks, good results were found for ascending a staircase, standing up from a chair, walking speed, and balance ${ }^{14}$. The results of these previous studies are in agreement with the results of this study in which walking and balancing abilities were improved by muscle strength training. In addition, the effect and importance of treadmill exercise for hemiplegic patients were mentioned in a previous study related to treadmill exercise, which reported the advantage of preventing the risk of fall for the patients ${ }^{15}$. Walking speed, cadence, and symmetry of stroke patients were improved after treadmill walking exercise ${ }^{16)}$. Moreover, walking speed was measured in a ground walking exercise group and a treadmill walking exercise group separately and the result showed that walking speed was significantly increased in the treadmill walking exercise group over the ground walking exercise group ${ }^{17)}$. One reported that walking speed and endurance were significantly increased when chronic hemiplegic patients performed treadmill walking exercise $^{18)}$. This result is similar to the improved walking ability and balancing ability gained by treadmill walking in this study.

There was no significant difference between the two groups when the differences of the $10 \mathrm{~m}$ walking test, TUG, BBS, and dynamic average balance before and after the experiment were compared. This result indicates that both types of exercise were effective, though neither can be considered more effective than the other at improving the walking and balance ability of stroke patients. The $p$ values of the results of each group after the exercise show that the improvement in MSG was more significant than that in TWG, showing the importance and practicality of lower extremity muscle strengthening exercise. Further studies may be necessary to develop a more systematic treatment program using muscle-strengthening equipment which depends on resistance intensity and exercise duration.

\section{REFERENCES}

1) Lipert J, Brouder H, Wolfgang HR, et al.: Treatment-induced cortical reorganization after stroke in humans. Stroke, 2003, 31: 1210-1216.

2) Frontera W, Sliver J, Rizzo T: Essentials of physical medicine and rehabilitation. Philadelphia: Hanley \& Belfus 2002, pp778-783.

3) Visintin M, Barbeau H, Mayo NE, et al.: A new approach to retrain gait in stroke patients through body weight support and treadmill stimulation. Stroke, 1998, 29: 1122-1128.

4) Dobkin BH, Sullivan KJ, Knowlton BJ: Step training with body weight support: effect of treadmill speed and practice paradigms on poststroke locomotor recovery. Arch Phys Med Rehabil, 2002, 83: 683-691.

5) Moseley AM, Stark A, Cameron ID, et al.: Treadmill training and body weight support for walking after stroke. Stroke, 2003, 34:3006

6) Waagfjord J, Levangle PK, Certo CM: Effect of treadmill training on gait in a hemiparetic patients. Phys Ther, 1990, 70: 549-560.

7) Sharp SA, Brouwer BJ: Isokinetic strength training of the hemiparetic knee: effects on function and spasticity. Achieves of Physical Medicine and Rehabilitation, 1997, 78: 1231-1236.

8) Kim HC: The effects of exercises to develope muscular strength legs of aged people to maintain the sense of balance. The Korea journal of sport science, 2003, 12: 731 - 741 .

9) Peggy R, Trueblood: Partial body weight treadmill training in persons with chronic stroke. NeuroRehabilitation, 2001, 16: 141-153.

10) Salbach NM, Mayo NE, Wood-Dauphinee S, et al.: A task-oriented intervention enhances walking distance and speed in the first year post stroke : A randomized controlled trial. Clin Rehabi, 2004, 18: 509-519.

11) Fabio RPD: Adaptation of postural stability following stroke. Topics Stroke Rehabil, 1997, 3: 62-75.

12) Teixeira-Salmela LF, Olney SJ, Nadeau S, et al.: Muscle strengthening and physical conditioning to reduce impairment and disability in chronic stroke survivors. Arch Phys Med Rehabil, 1999, 80: 1211-1218. 
13) Teixeira-Salmela LF, Nadeau S, Mcbride I, et al.: Effects of muscle strengthening and physical conditioning training on temporal kinematic and kinetic variables during gait in chronic stroke survivors. Rehab Med, 2001, 33: $53-60$

14) Badics E, Wittmann A, Rupp M, et al.: Systematic muscle building exercise in the rehabilitation of stroke patients. NeuroRehabilitation, 2002, 17:211214

15) Hassid E, Rose D, Commisarow J, et al.: Improved gait symmetry in hemiparetic stroke patients induced during body weight-supported treadmil stepping. Journal Neuro Rehabil, 1997, 11: 21-26.
16) Silver KH, Macko RF, Forrester LW, et al.: Effects of aerobic treadmill training on gait velocity, cadence, and gait symmetry in chronic hemiparetic stroke: a preliminary report. NeuroRehabilitation and Neural Repair, 2000, 14: 65-71.

17) Laufer $Y$, Dickstein R, Chefez Y, et al.: The effect of treadmill training on the ambulation of stroke survivors in the early stage of rehabilitation. Journal of rehabilitation Research and Development, 2001, 38: 385-399.

18) Kim SY: Effect of treadmill training on walking velocity and gait endurance in patients with chronic hemiplegia. The Korean Society of Physical Therapy, 2004, 16:221-228. 